\title{
A scaling approach to Budyko's framework and the complementary relationship of evapotranspiration in humid environments: case study of the Amazon River basin
}

\author{
A. M. Carmona ${ }^{1}$, G. Poveda ${ }^{1}$, M. Sivapalan ${ }^{2,3}$, S. M. Vallejo-Bernal ${ }^{1}$, and E. Bustamante ${ }^{4}$ \\ ${ }^{1}$ Department of Geosciences and Environment, Universidad Nacional de Colombia, Sede Medellín, Medellín, Colombia \\ ${ }^{2}$ Department of Civil and Environmental Engineering, University of Illinois at Urbana-Champaign, Urbana, Illinois, USA \\ ${ }^{3}$ Department of Geography and Geographic Information Science, University of Illinois at \\ Urbana-Champaign, Urbana, Illinois, USA \\ ${ }^{4}$ Department of Mathematics, Universidad Nacional de Colombia, Sede Medellín, Medellín, Colombia
}

Correspondence to: A. M. Carmona (amcarmo0@unal.edu.co)

Received: 23 September 2015 - Published in Hydrol. Earth Syst. Sci. Discuss.: 16 October 2015

Revised: 12 January 2016 - Accepted: 13 January 2016 - Published: 3 February 2016

\begin{abstract}
This paper studies a 3-D state space representation of Budyko's framework designed to capture the mutual interdependence among long-term mean actual evapotranspiration $(E)$, potential evapotranspiration $\left(E_{\mathrm{p}}\right)$ and precipitation $(P)$. For this purpose we use three dimensionless and dependent quantities: $\Psi=E / P, \Phi=E_{\mathrm{p}} / P$ and $\Omega=E / E_{\mathrm{p}}$. This 3-D space and its 2-D projections provide an interesting setting to test the physical soundness of Budyko's hypothesis. We demonstrate analytically that Budyko-type equations are unable to capture the physical limit of the relation between $\Omega$ and $\Phi$ in humid environments, owing to the unfeasibility of $E_{\mathrm{p}} / P=0$ when $E / E_{\mathrm{p}} \rightarrow 1$. Using data from 146 sub-catchments in the Amazon River basin we overcome this inconsistency by proposing a physically consistent power law: $\Psi=k \Phi^{e}$, with $k=0.66$, and $e=0.83\left(R^{2}=0.93\right)$. This power law is compared with two other Budyko-type equations. Taking into account the goodness of fits and the ability to comply with the physical limits of the 3-D space, our results show that the power law is better suited to model the coupled water and energy balances within the Amazon River basin. Moreover, $k$ is found to be related to the partitioning of energy via evapotranspiration in terms of $\Omega$. This suggests that our power law implicitly incorporates the complementary relationship of evapotranspiration into the Budyko curve, which is a consequence of the dependent nature of the studied variables within our 3-D space. This scaling approach is also consistent with the asymmetrical nature of the com-
\end{abstract}

plementary relationship of evapotranspiration. Looking for a physical explanation for the parameters $k$ and $e$, the interannual variability of individual catchments is studied. Evidence of space-time symmetry in Amazonia emerges, since both between-catchment and between-year variability follow the same Budyko curves. Finally, signs of co-evolution of catchments are explored by linking spatial patterns of the power law parameters with fundamental characteristics of the Amazon River basin. In general, $k$ and $e$ are found to be related to vegetation, topography and water in soils.

\section{Introduction}

The pioneering work of Budyko (1974) introduced a theoretical framework to link the long-term average water and energy balances in a river basin considering the dominant controls on actual evapotranspiration $(E)$, assuming that the water balance is mostly governed by water availability (precipitation, $P$ ) and energy availability (represented for convenience by potential evapotranspiration, $E_{\mathrm{p}}$ ). According to Budyko, mean annual $E$ approaches mean annual $P$ as the climate becomes drier, provided that water storage change in the catchment is negligible. Such water and energy coupling is represented in a bi-dimensional space relating two nondimensional variables, the evapotranspiration ratio $(E / P)$, 
and the aridity index $\left(E_{\mathrm{p}} / P\right)$, such that

$$
\frac{E}{P}=f\left(\frac{E_{\mathrm{p}}}{P}\right)
$$

The ratio $E / P$ can be considered a measure of the longterm mean annual water balance in a catchment, since it is the fraction of the water falling as precipitation that is partitioned into evapotranspiration. On the other hand, $E_{\mathrm{p}} / P$ is a measure of the long-term mean climate being a ratio of energy availability $\left(E_{\mathrm{p}}\right)$ to water availability $(P)$. Small values of $E_{\mathrm{p}} / P\left(E_{\mathrm{p}} / P<1\right)$ are associated with humid catchments where precipitation is significant and the energy supply is the limiting factor for evapotranspiration. Conversely, large values of $E_{\mathrm{p}} / P\left(E_{\mathrm{p}} / P>1\right)$ are found in arid regions where precipitation is low and evapotranspiration is limited by water supply. Budyko $(1958,1974)$ carried out an empirical analysis of long-term mean annual water balances in a large number of environments around the world and demonstrated that the water balance of catchments in different climatic regions provided a nice fit to the curve presented in Fig. 1 (called the Budyko curve), bounded by the relevant physicomathematical water and energy limits:

$$
\left\{\begin{array}{l}
\frac{E}{P}=\frac{E_{\mathrm{p}}}{P} \text { for } \quad \frac{E_{\mathrm{p}}}{P}<1 \quad \text { (energy-limited evapotranspiration), } \\
\frac{E}{P}=1 \text { for } \frac{E_{\mathrm{p}}}{P}>1 \quad \text { (water-limited evapotranspiration). }
\end{array}\right.
$$

Budyko proposed an equation to model the mean annual water balance (Eq. 1, and Fig. 1) building on two equations previously formulated by Schreiber (1904) and Ol'dekop (1911). The formulation proposed by Schreiber (1904) implied that the evaporation ratio asymptotically approached unity $(E / P \rightarrow 1)$ for large values of the aridity index, given that in extremely arid regions all precipitation is essentially converted into evapotranspiration $(E=P)$. In other words, in arid regions, available energy greatly exceeds the amount required to evaporate the entire annual precipitation, $P$, and annual $E$ approaches annual $P$, whereas in humid regions available energy, $E_{\mathrm{p}}$, is only a fraction of the amount required to evaporate the annual precipitation, $P$, and thus annual $E$ approaches annual $E_{\mathrm{p}}$. Ol'dekop (1911) developed a similar relationship albeit using a hyperbolic tangent relationship. Budyko found that Schreiber's equation underestimated evapotranspiration while Ol'dekop's equation overestimated it, and thus he set forth a new equation using the geometric mean between those two, given as

$$
\frac{E}{P}=\left[\frac{E_{\mathrm{p}}}{P} \tanh \left(\frac{P}{E_{\mathrm{p}}}\right)\left(1-\exp \left(-\frac{E_{\mathrm{p}}}{P}\right)\right)\right]^{1 / 2}
$$

which satisfies the previously discussed limits (Eq. 2). Diverse authors have derived equations to further develop Budyko's framework (Mezentsev, 1955; Pike, 1964; Fu, 1981; Choudhury, 1999; Yang et al., 2008; Zhou et al., 2015). In particular, Yang et al. (2008) mathematically derived a general solution for the set of partial differential equations

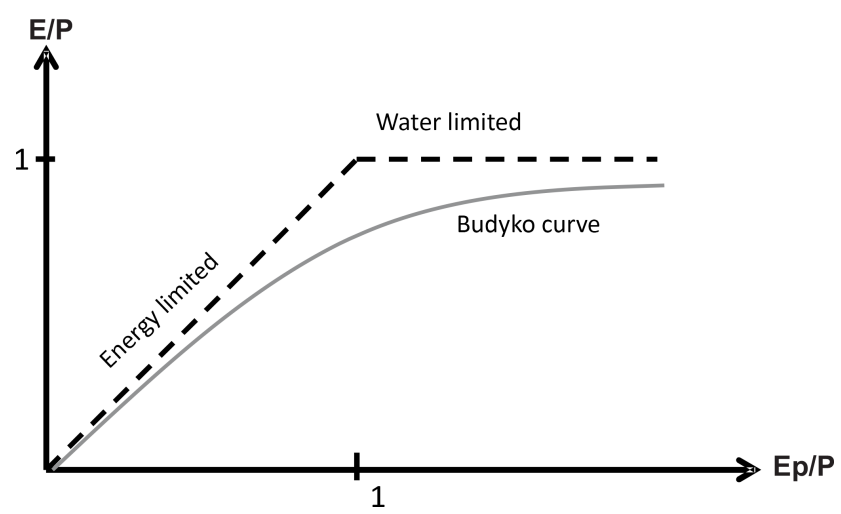

Figure 1. Budyko curve relating the evapotranspiration ratio $(E / P)$ to the aridity index $\left(E_{\mathrm{p}} / P\right)$, and their limits for wet (energy-limited) and dry environments (water-limited).

representing the coupled water and energy balances in catchments, which in terms of the evapotranspiration ratio, $(E / P)$, and the aridity index, $\left(E_{\mathrm{p}} / P\right)$, can be written as

$$
\frac{E}{P}=\left(1+\left(\frac{E_{\mathrm{p}}}{P}\right)^{-n}\right)^{-\frac{1}{n}}
$$

where $n$ is a parameter that captures the combined effects of river basin and vegetation characteristics.

The coupled water and energy balance framework postulated by Budyko $(1958,1974)$ has provided a rich setting to address fundamental questions in hydrology such as water availability, and water resources management and streamflow prediction in ungauged basins (Arora, 2002; Ma et al., 2008; Zhang et al., 2008; Renner and Bernhofer, 2012; Renner et al., 2012; Roderick and Farquhar, 2011; Wang and Hejazi, 2011; Blöschl et al., 2013; Greve et al., 2015). In particular, it has been used at various spatial and temporal scales to perform diagnostic analyses of the long-term mean annual water balances in catchments and to study the interactions between hydro-climate, soil, vegetation and topography and their role in water balance variability (Milly, 1994; Zhang et al., 2001; Yang et al., 2007; Donohue et al., 2007). Nevertheless, all of these studies have focused on the 2-D approach of the Budyko hypothesis, assuming that $P, E$, and $E_{\mathrm{p}}$ (but mostly $P$ and $E_{\mathrm{p}}$ ) are independent of each other. For example, the analytical derivation of the Budyko equation by Yang et al. (2008) (Eq. 4) was carried out under the assumption that $\partial P / \partial E_{\mathrm{p}}=0$. Such an assumption is questionable given the well-known complementary relationship of evapotranspiration (Bouchet, 1963; Morton, 1983; Hobbins et al., 2001; Xu and Singh, 2005; Szilagyi and Jozsa, 2009; Han et al., 2014; Lintner et al., 2015), but also having in mind the important role of evapotranspiration in the recycling of precipitation (Shuttleworth, 1988; Elthair and Bras, 1994; Dominguez et al., 2006; Zemp et al., 2014). 
This paper presents a 3-D generalization of the Budyko hypothesis, intended to capture the mutual interdependence among $E, E_{\mathrm{p}}$, and $P$ by involving the complementary relationship of evapotranspiration. We achieve this by studying a three-parameter space defined by three dimensionless and dependent quantities: $\Phi=E_{\mathrm{p}} / P, \Psi=E / P$, and $\Omega=$ $E / E_{\mathrm{p}}$. Towards that aim the paper is organized as follows: Sect. 2 provides the methods used for this study including the justification for the 3-D generalization of Budyko's framework. This generalization is interpreted from the perspective of the complementary relationship and reveals a physical inconsistency implied in Budyko's framework for humid environments. Data sets in which our methods are applied are also described in Sect. 2, namely agro-climatic stations around the world and catchments in the continental US of America, China and Amazonia. We focus our research on the Amazon River basin as a case study recognizing the need to further test the validity of the Budyko framework and the complementary relationship in humid environments. Application to the Amazon is also motivated by it being the largest river basin in the world, by its tropical location, and by the mostly undisturbed condition of its natural vegetation. The results of the analyses and their discussion are presented in Sect. 3. Finally, Sect. 4 presents the main conclusions drawn from the study.

\section{Methods and data}

\subsection{Rationale for a 3-D generalization of the Budyko hypothesis}

Motivated by Budyko's coupling between the water and energy balances and considering the mutual inter-dependence between $E, E_{\mathrm{p}}$ and $P$, we propose to organize the analysis within a 3-D space defined by three dimensionless variables: $\Phi=E_{\mathrm{p}} / P, \Psi=E / P$, and $\Omega=E / E_{\mathrm{p}}$. Recall that $\Phi$ and $\Psi$ are, respectively, the aridity index, and the evapotranspiration ratio. In turn, $\Omega$ denotes the partitioning of energy via evapotranspiration, understanding potential evapotranspiration as the physical upper limit for $E$ (Thornthwaite, 1948). Thus, $\Omega$ is introduced in the 3-D space to capture the complementary relationship existing between $E$ and $E_{\mathrm{p}}$. Briefly, this approach combines the analysis of the annual water balance based on the Budyko hypothesis with the energy balance from the perspective of the complementary relationship of evapotranspiration, as has also been attempted previously by Yang et al. (2006) and Lintner et al. (2015).

\subsubsection{The complementary relationship of evapotranspiration}

A strong body of literature has been dedicated to study the relationship between $E$ and $E_{\mathrm{p}}$, in particular the complementary relationship hypothesis (Bouchet, 1963; Morton, 1983; Hobbins et al., 2001; Xu and Singh, 2005; Szilagyi and Jozsa,
2009; Han et al., 2014). Before the study of Bouchet (1963) it was thought that a higher $E_{\mathrm{p}}$ implied a greater $E$. He corrected this misconception based on energy balance arguments, demonstrating that as a surface dries up from initially wet conditions, $E_{\mathrm{p}}$ increases while $E$ decreases as the available water drops. This can be explained because a decrease in evapotranspiration from a dry surface will make the overlying air warmer and drier, thus increasing available energy and producing a compensatory increase in $E_{\mathrm{p}}$. On the other hand, an increase in $P$ increases the availability of surface water, and thus $E$ increases. Since $E$ is a cooling process it causes the surrounding air to cool and to become wetter, and consequently this produces a decrease in $E_{\mathrm{p}}$. Finally, if the surface is sufficiently moist, $E=E_{\mathrm{p}}$. This is known as the complementary relationship of evapotranspiration. Mathematically, the complementary relationship is often assessed as those changes in $E$ given changes in $E_{\mathrm{p}}$ $\left(\partial E / \partial E_{\mathrm{p}}\right)$. Bouchet (1963) proposed that such a relation is inverse and symmetrical for dry environments $\partial E / \partial E_{\mathrm{p}}=1$, whereas $\partial E / \partial E_{\mathrm{p}}=0$ for very humid environments, but it has been shown that such a relation is not perfectly symmetrical (Granger, 1989; Kahler and Brutsaert, 2006; Szilagyi, 2007; Lintner et al., 2015).

\subsubsection{A physical inconsistency of Budyko-type equations}

The proposed 3-D state space and its 2-D projections ( $\Psi$ vs. $\Phi, \Psi$ vs. $\Omega$ and $\Phi$ vs. $\Omega$ ) provide an interesting setting to test for the physical soundness of Budyko's original hypothesis. In terms of our dimensionless variables, Budyko's Eq. (3) and Yang et al.'s Eq. (4) can be written, respectively, as

$\Psi=\left[\Phi \tanh \left(\Phi^{-1}\right)(1-\exp (-\Phi)]^{1 / 2}\right.$

and

$\Psi=\left(1+\Phi^{-n}\right)^{-1 / n}$.

Using Eq. (6), the relationship between $\Omega=E / E_{\mathrm{p}}$ and $\Phi=E_{\mathrm{p}} / P$ can be expressed as

$\Phi=\left(\frac{1}{\Omega^{n}}-1\right)^{1 / n}$.

Analytically, for very humid environments, if $\Omega \rightarrow 1$ it can be demonstrated that

$\lim _{\Omega \rightarrow 1}\left(\frac{1}{\Omega^{n}}-1\right)^{1 / n}=0$.

The same result is obtained if instead of Eq. (6) we use Eq. (5) or even the equation proposed by Fu (1981). Thus, traditional Budyko-type equations require that for humid environments, when $\Omega \rightarrow 1, \Phi=0$. This theoretical prediction of Budyko's framework entails a physical inconsistency in 
the relationship between $\Omega=E / E_{\mathrm{p}}$ and $\Phi=E_{\mathrm{p}} / P$, that is, in the relationship between the partitioning of energy and the aridity index. Budyko-type equations (Eq. 7) suggest two possibilities for the case of $\Phi=E_{p} / P=0$ : (i) that $E_{p}$ can be zero (negligible atmospheric demand), or (ii) that $P$ approaches infinity. However, even in the most humid regions of the world (i.e., Lloró, Colombia, or Cherrapunji, India) there is always a potential for evapotranspiration, and even though rainfall is very high (up to $12000-13000 \mathrm{~mm} \mathrm{yr}^{-1}$ ), it is never infinite. We consider this to be a physical inconsistency of Budyko's theoretical framework for humid environments. Therefore, a different approach is in order: this provides the main motivation for this study.

\subsection{Data sets}

Data used for this study consisted of 3123 agro-climatic stations from the CLIMWAT 2.0 database, a joint product of the Water Development and Management Unit and the Climate Change and Bioenergy Unit of the Food and Agriculture Organization of the United Nations (FAO). CLIMWAT 2.0 includes meteorological data from 144 countries providing long-term monthly mean values of seven climatic parameters, including maximum and minimum temperature, monthly rainfall and potential evapotranspiration. All variables are direct observations or conversions of observations, except for $E_{\mathrm{p}}$, which is calculated using the PenmanMonteith equation (Monteith, 1965). The CLIMWAT 2.0 database can be freely downloaded from http://www.fao.org/ $\mathrm{nr} /$ water/infores_databases_climwat.html. Long-term mean actual evapotranspiration $(E)$ was calculated by means of Turc's equation (Turc, 1954), which requires information on mean annual precipitation and temperature. $E$ was also calculated using Budyko's Eq. (3) with data and estimates of mean annual $P$ and $E_{\mathrm{p}}$.

Furthermore, information from 419 catchments in the continental US belonging to the MOPEX data set (Duan et al., 2006) and from 108 catchments in China (Yang et al., 2007) are also included in our analysis. The MOPEX data set contains daily time series of hydrologic data, with $P$ processed by the Hydrology Laboratory of the National Weather Service (NWS) and $E_{\mathrm{p}}$ based on the National Oceanic and Atmospheric Administration (NOAA) Evaporation Atlas (Farnsworth et al., 1982). On the other hand, the Chinese data set provides information of $P$ and $E_{\mathrm{p}}$ (calculated with the Penman equation, Penman, 1948) in catchments with relatively little human interference in the form of dams and irrigation projects. For both data sets $E$ was first calculated by means of the long-term water balance equation using information of long-term precipitation and river runoff ( $E=P-Q$ ), and also using Budyko's Eq. (3). In terms of the aridity index $(\Phi)$, the MOPEX river basins span a wide range of climates with values of $\Phi$ from 0.27 to 4.97 , while the Chinese river basins are all arid $(\Phi>1)$.

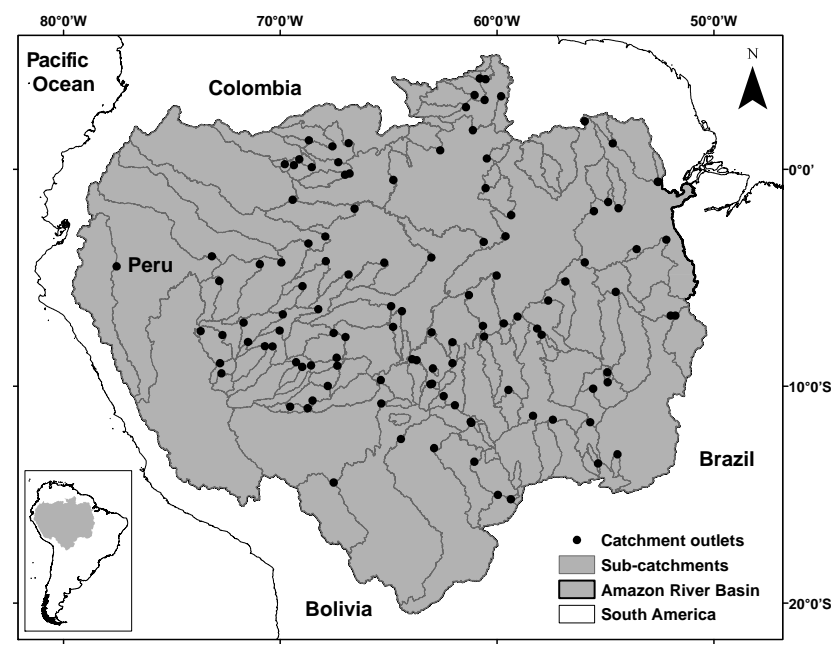

Figure 2. Location of the study area and the 146 sub-catchments in the Amazon River basin.

To represent hydrologic characteristics in humid environments we used data from 146 catchments in the Amazon River basin. For this purpose information of $P$ and $E$ was obtained from the AMAZALERT project in Amazonia (http: //www.eu-amazalert.org/home). Specifically $P$ was obtained from the Observation Service SO-HYBAM (formerly Environmental Research Observatory ORE-HYBAM) data set available at http://www.ore-hybam.org/. Information on precipitation in the Amazon River basin was also available from the Tropical Rainfall Measuring Mission (TRMM), but data from HYBAM were chosen because of the need for a longer data set. It is important to emphasize that for these catchments $E$ was not estimated via the long-term water balance equation but from an independent data set compiled by the Max Plank Institute (MPI) using a global monitoring network with meteorological and remote sensing observations (Jung et al., 2010). $E_{\mathrm{p}}$ was calculated using the Hargreaves equation (Hargreaves et al., 1985) following Trabucco and Zomer (2009) and Vallejo-Bernal et al. (2016), who showed that for South America, this model based on temperature and extra-terrestrial radiation is one of the most appropriate methods to estimate $E_{\mathrm{p}}$. Specifically, according to VallejoBernal et al. (2016), data limitation is not the only reason why Hargreaves' equation works better in Amazonia. This is because estimates of $E_{\mathrm{p}}$ from databases such as the one from the Climatic Research Unit (CRU) tend to underestimate this variable, as evidenced in the annual regime curves of $E$ vs. $E_{\mathrm{p}}$. For the Amazon River basin $P, E$ and $E_{\mathrm{p}}$ were available on a monthly scale (mm month ${ }^{-1}$ ) covering 27 years (19822007) of information for all the catchments. Figure 2 shows the location of the study area and the gauging stations defining the set of 146 sub-catchments.

In addition, three landscape features were chosen based on available information to depict some of the main characteristics of the Amazon River basin, including topogra- 

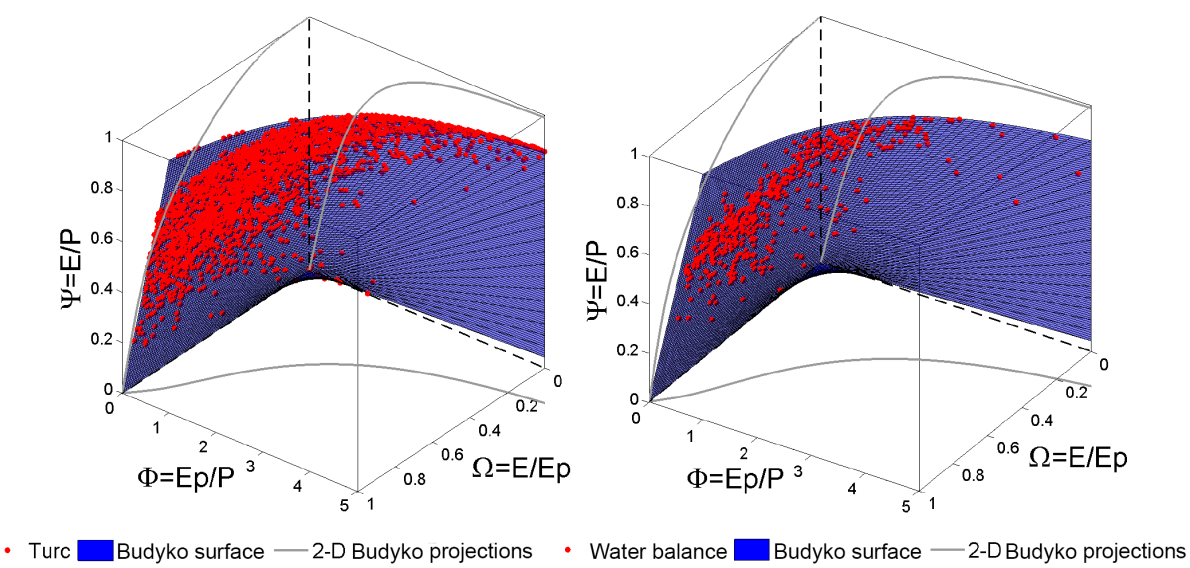

Figure 3. The 3-D state space for the FAO agro-climatic stations (left panel) and catchments in the US and China (right panel). Grey lines represent the 2-D projections of the blue surface estimated with $E$ calculated using Eq. (3).

phy, groundwater levels and vegetation. To represent topography, a digital elevation model (DEM) processed by the United States Geological Survey (USGS) and available at http://hydrosheds.cr.usgs.gov/index.php was used to calculate the mean elevation (ma.s.l.) for each sub-catchment in the Amazon River basin, which ranges from 0 to $6250 \mathrm{~m}$ a.s.l. in the Andes Mountain range. As for groundwater levels, the climatological mean water table depth simulated by Fan et al. (2013) was used. This water table depth is a result of the long-term hydrologic balance between the groundwater recharge and the lateral, geologic, and topographically induced flow below and parallel to the water table and shows values from $0 \mathrm{~m}$ near the bodies of water (rivers and permanent wetlands) to $818 \mathrm{~m}$ up in the Andes. Regarding vegetation, we used the MODIS-based Maximum Green Vegetation Fraction data set generated by Broxton et al. (2014) and available at http://landcover.usgs.gov/green_veg.php. This data set comprises the mean annual maximum green vegetation fraction from 2001 to 2012, based on the MOD13A2 normalized difference vegetation index (NDVI). In the Amazon River basin values range from $0 \%$ (no vegetation cover) to 100 (100\% vegetation cover), but most values range between 80 and $100 \%$.

\section{Results and discussion}

\subsection{The 3-D view of Budyko's framework and its 2-D projections}

Figure 3 shows our 3-D space $(\Phi-\Omega-\Psi)$ within Budyko's framework for the FAO agro-climatic stations (Fig. 3, left panel) and catchments in the US and China (Fig. 3, right panel). Red dotes represent observed data with $E$ calculated with Turc's equation or the water balance equation, respectively. In both cases, despite the scatter observed in the plots, it can be seen that there is a surface that captures the data sets within the proposed 3-D parameter space, which was ob- tained by estimating $E$ using Budyko's Eq. (3). Grey lines on the faces of the "cubes" represent the 2-D projections of the surface. Taking into consideration how the three dimensionless variables were defined and that they are not independent of each other, the equation of the surface (Fig. 3) can be easily obtained as $\Psi=\Phi \Omega$. Figure 3 also shows that red dots are limited to specific parts of the surface. This means that although this surface comes from a valid mathematical equation it does not necessarily mean that all parts of the surface are physically feasible in nature. For example, there are no environments with low $\Omega$ and low $\Phi$ at the same time or environments with low $\Psi$ and high $\Phi$ simultaneously. This leads us to further explore the bi-dimensional projections of our 3-D space.

Figure 4 shows the three bi-dimensional projections of the proposed 3-D space: $\Psi$ vs. $\Phi, \Psi$ vs. $\Omega$ and $\Phi$ vs. $\Omega$. Blue dots denote actual data for the FAO agro-climatic stations (Fig. 4a-c) and for the US-China catchments (Fig. 4df). Thick black lines and dashed black lines represent the Budyko curves (and their corresponding projections on the bi-dimensional spaces of our 3-D approach) using Eqs. (3) and (4) with $n=2$, respectively.

Figure $4 \mathrm{a}$ and $\mathrm{d}$ present the relationship $\Psi$ vs. $\Phi$ (traditional Budyko approach). On these panels, the Budyko curve has two physically consistent limits denoting energylimited and water-limited evapotranspiration (Eq. 2). Despite the observed scatter, which could be explained by other factors affecting $E$ such as soils, vegetation and topography, amongst others, (Milly, 1994; Zhang et al., 2001; Yang et al., 2007; Donohue et al., 2007), data from agro-climatic stations (Fig. 4a) and from catchments (Fig. 4d) follow the Budyko curve. Figure $4 \mathrm{~b}$ and e, illustrate the relationship $\Psi$ vs. $\Omega$, which also has two physically consistent limits. The first limit is a vertical line at $\Omega=1$, because physically $E$ can never exceed $E_{\mathrm{p}}$. Thus, $\Omega=1$ corresponds to very humid environments where precipitation is large, there is no water limitation and $E=E_{\mathrm{p}}$. The second physical limit in 

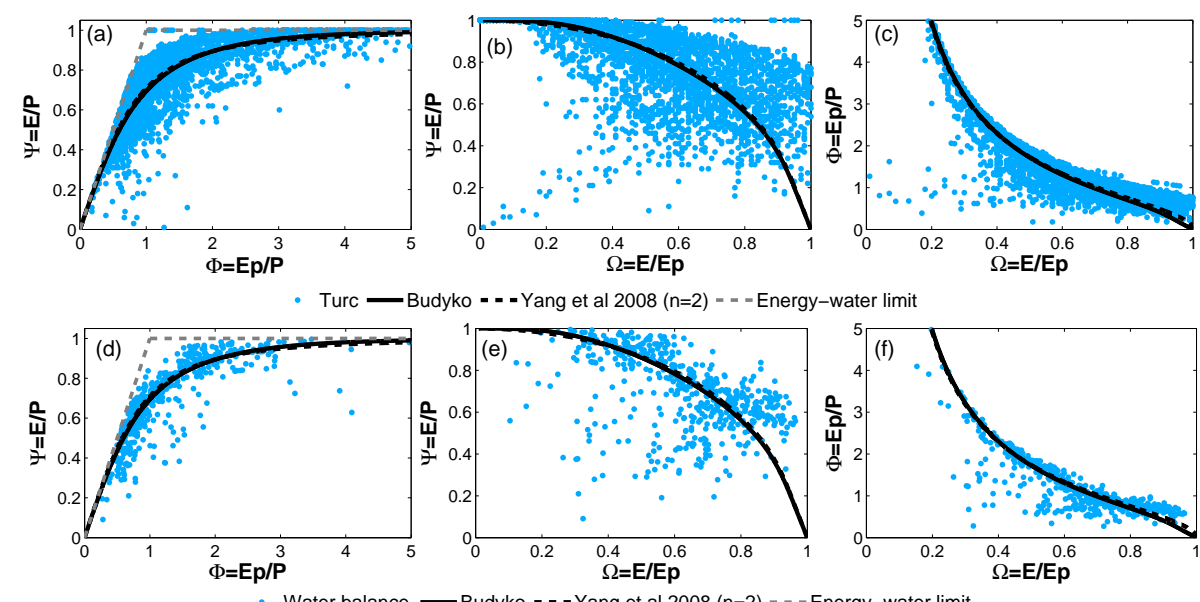

Figure 4. Bi-dimensional projections of the 3-D space for the FAO agro-climatic stations (a-c) and for catchments in the US and China (d-f).

Fig. 4b and e is a horizontal line at $\Psi=1$, where $E=P$, since on the long-term timescale, $E$ should not exceed $P$. In summary, in arid regions $\Psi$ is large (with a maximum value at $\Psi=1$ ) and $\Omega$ is small, whereas in humid regions $\Omega$ is large (with a maximum value at $\Omega=1$ ) and $\Psi$ is low. Figure $4 \mathrm{c}$ and $\mathrm{f}$ show the relationship between the remaining dimensionless variables, $\Phi$ and $\Omega$, which were related previously using Eq. (7) and for which the physical inconsistency was found. This relationship has one physical limit at $\Omega=1$, for very humid regions where $E=E_{\mathrm{p}}$. It was demonstrated mathematically that Eq. (7) requires that for $\Omega \rightarrow 1, \Phi=0$, as revealed by both theoretical black curves in Fig. $4 \mathrm{c}$ and $\mathrm{f}$. However, actual data never reach zero at $\Omega=1$, confirming what was evidenced in Sect. 2.1.2. Given this physical inconsistency, found particularly in wet environments, we propose a new way to address the Budyko hypothesis in humid regions such as the Amazon River basin, as explained next.

\subsection{A scaling approach to Budyko's framework in humid environments}

For many years power laws have been popular in the geosciences, mainly because of their simplicity, unique mathematical properties and because of the surprisingly physical mechanisms they represent (Parzen, 1999). Many hydrological, climatic, ecological processes, among others, exhibit emergent patterns that manifest as power laws (Gupta and Dawdy, 1995; Rodriguez-Iturbe and Rinaldo, 1997; Sposito, 1998; Turcotte, 1997; Brown et al., 2002), which reveal certain types of universalities emerging from the complexity of nature (Brown et al., 2002). By fitting empirical relationships using power laws, one assumes that the system is essentially self-similar or fractal (Mandelbrot, 1983), which suggests that the main characteristics of the system exhibit an invariant organization that remains the same over a wide range of scales.
With the purpose of overcoming the physical inconsistency of Budyko's framework for the relationship between $\Phi$ vs. $\Omega$ in humid environments, we study the proposed 3-D Budyko space (and its bi-dimensional projections) using data from 146 catchments in the Amazon River basin, with values of $\Phi$ ranging from 0.43 to 1.55 . Considering the behavior of the data and bearing in mind all the physical limits of the Budyko hypothesis, we suggest the following power law to represent the Budyko curve for the studied catchments:

$\Psi=k \Phi^{e}$.

Using a nonlinear least squares regression algorithm with confidence bounds set at a $95 \%$ confidence level, the coefficient and scaling exponent were estimated as $k=0.66$ and $e=0.83\left(R^{2}=0.93\right)$, respectively. Since our interest is to capture the behavior of the data in humid environments in the best way possible, we compared the performance of Eq. (9) with two other approaches. First, we used Eq. (6) (Yang et al., 2008) to model the data in the Amazon River basin. However, instead of assuming $n=2$, we used the same nonlinear least squares regression algorithm and obtained the best value of $n$ for this data set, which turned out to be $n=1.58$ $\left(R^{2}=0.85\right)$. Then, we followed the study by Cheng et al. (2011), who justified the use of linear relationships to address the Budyko hypothesis. For this approach we fitted the data to a linear relationship $\Psi=a \Phi+b$, with $a=0.55$ and $b=0.11\left(R^{2}=0.91\right)$. However, it is worth remarking that Cheng et al. (2011) only assessed the inter-annual variability of the water balance rather than long-term mean values.

Our next step was to test the 3-D generalization of Budyko's framework in the Amazon River basin, focusing on its three bi-dimensional projections (Fig. 5), with emphasis on the relationship between $\Phi$ and $\Omega$, which exhibited the physical inconsistency. Figure 5a shows the traditional Budyko curve for the 146 sub-catchments within the Amazon River basin (blue dots) and the results of the parameters 

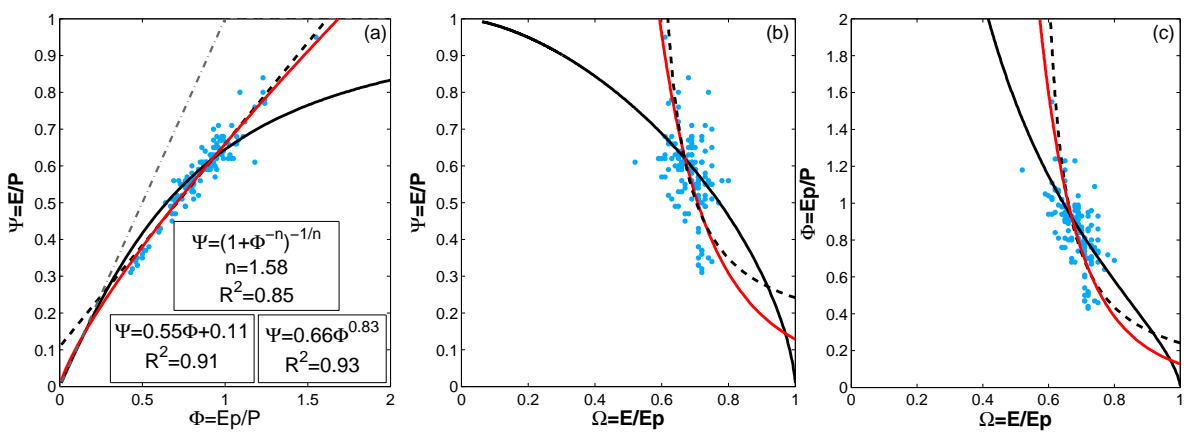

- Data Amazon — Budyko (Yang et al 2008) - - - Linear (Cheng et al 2011) — Power Law - - - Energy limit

Figure 5. Bi-dimensional projections of the 3-D space for the 146 Amazon River sub-catchments.

obtained with Eqs. (6), (9) and the linear relationship. Figure $5 \mathrm{~b}$ and $\mathrm{c}$ show the remaining bi-dimensional projections of our 3-D space with actual data and the theoretical curves that come from the previously mentioned equations. From Fig. 5a-c, and taking into account the goodness of fit, it can be seen how both the power law and the linear relationship are better suited to model the data in these humid catchments. Also, both approaches theoretically overcome the physical inconsistency found for the relationship between $\Phi$ and $\Omega$ (Fig. 5c), since unlike the thick black line (Yang et al., 2008), the dashed black line (Cheng et al., 2011) and the thick red line (Power law) do not approach zero as $\Omega$ increases. Nevertheless, the linear relationship does not fully comply with the energy limit in the Budyko curve, as can be seen in Fig. 5a. In fact, it can be seen that in order to fulfill the energy limit, its intercept would have to be restricted to $b=0$. For these reasons, we conclude that the power law is the best equation among the three of them to capture the long-term mean coupled water-energy balances in Amazonia.

One of the reasons that explains why both the power law and the linear relationship work better than traditional Budyko-type equations, which was first pointed out by Cheng et al. (2011), is that these relationships have two parameters $(k, e$ and $a, b)$, while Eq. (6) has only one $(n)$. Particularly in this case, since we are dealing with humid environments, it also has to do with the way these catchments partition water and energy, in the sense that for most of these catchments in Amazonia evapotranspiration is energylimited rather than water-limited. This observation locates the Amazonian catchments closer to the energy limit in the Budyko curve (grey dashed line in Fig. 5a), along its "linear $1: 1$ " part, and this makes data suitable for a power law.

With these results in mind, several questions arise: how do the parameters change from catchment to catchment? Are the values of these parameters in the long term the same as at the inter-annual scale? Can any of these parameters be explained by landscape features or catchment properties? In order to answer these questions our next goal is to study the interannual variability of the coupled water and energy balances in Amazonia. By inter-annual variability we mean the year- to-year variations within each one of the 146 sub-catchments, as explained in the following section.

\subsection{Assessing inter-annual variability of the coupled water and energy balances in the Amazon River basin}

With 27 years of information for each of the 146 subcatchments in Amazonia, the inter-annual variability of the water balance is studied. Once more the three approaches that were tested before are compared. For this purpose, Eqs. (6), (9) and the linear relationship are fitted to the data, and thus the parameters $k, e, a, b$ and $n$ are obtained for each catchment. The first question that we will try to answer is whether the values of these parameters in the long term are the same as at the inter-annual scale in order to search for signs of space-time symmetry of the coupled water and energy balances (Sivapalan et al., 2011; Carmona et al., 2014; Perdigão and Blöschl, 2014). Later on, signs of catchment co-evolution will be explored by linking the parameters with characteristic landscape features within the Amazon River basin.

\subsubsection{Space-time symmetry}

In hydrology, the term space-time symmetry has been adopted when an equation or model can be used to depict between-catchment variability of long-term mean annual water balances and the corresponding between-year variability within individual catchments, thus implying ergodicity of the hydrological system at the catchment scale (Sivapalan et al., 2011; Carmona et al., 2014; Perdigão and Blöschl, 2014). Figure 6 presents a comparison of the long-term mean Budyko curve (Fig. 6a) and the inter-annual Budyko curve for the 146 catchments in Amazonia (Fig. 6b), as well as the results of the implementation of Eqs. (6), (9) and the linear relationship. Each triangle represents one catchment (Fig. 6a) and each dot represents 1 year of the 27 years of data of each catchment (Fig. 6b). It should be pointed out that Figs. 5a and 6a are essentially the same; however, in Fig. 6a catch- 

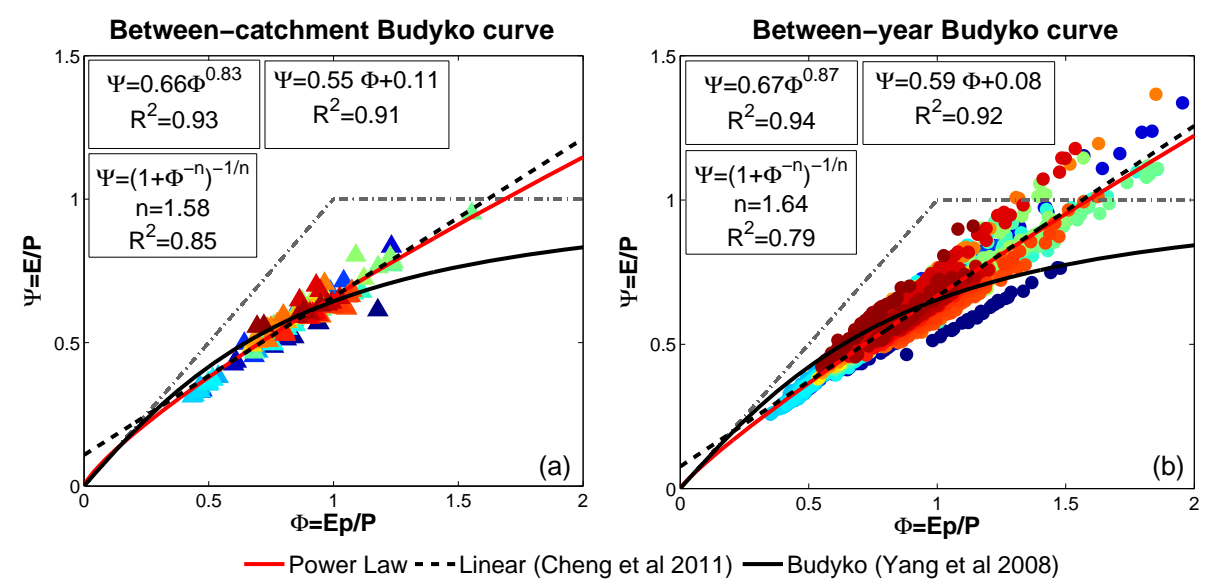

Figure 6. (a) Between-catchment variability of the long-term mean Budyko curve and (b) between-year variability of the Budyko curve. Colors denote different sub-catchments within Amazonia. The insets show the results of fitting Eqs. (6) and (9) and the linear relationship, with their respective parameters.

ments can be distinguished from each other by different colors. In the previous section we described how we used a nonlinear least squares regression algorithm to obtain the parameters for the three equations that are shown in Fig. 6a. Now, for the case of Fig. $6 \mathrm{~b}$, the procedure is the same, although all catchments with their 27 years of data were taken together as if they were a single data set. With confidence bounds set a $95 \%$ confidence level, the coefficient and scaling exponent of the power law, the slope and intercept of the linear relationship and the parameter from Eq. (6) were estimated as $k=0.67, e=0.87, a=0.59, b=0.08$ and $n=1.64$, respectively. These results appear to reveal that there is indeed space-time symmetry within these 146 catchments in the Amazon River basin, especially for the power law equation, given that the values of the parameters $k$ and $e$ do not seem to change much.

Moreover, for the case of the power law and the linear relationship, the scatter present in the inter-annual variability of the water balance does not seem to affect the goodness of fit, and actually both coefficients of determination increase ( $R^{2}=0.94$ and $R^{2}=0.92$, respectively); nevertheless, bearing in mind the physical limits of the Budyko framework that have been discussed throughout this paper, it can be seen once more how the linear relationship does not fully satisfy the energy limit at the inter-annual scale (Fig. 6b). The increase in the goodness of fit for both equations could be possibly attributed to an increase in data points and also because in Amazonia, the scatter in the inter-annual variability is evidenced somehow parallel to the energy limit, that is, in the direction of the power law and linear relationships (Fig. 6b). In contrast, the scatter present in the year-to-year variations does affect the performance of Eq. (6), as reflected in a decrease of $R^{2}$. In fact, in Amazonia, the inter-annual variability of the water balance diverges from the traditional Budyko curve as $\Phi$ increases (Fig. 6b). This is because while in arid environments moisture available for $E$ comes mostly from $P$ and $E / P \rightarrow 1$ as $E_{\mathrm{p}} / P$ increases, in humid environments there can be other sources of moisture besides $P$, such as water stored in soils and vegetation, which in the Amazon River basin can be significant. This is also the reason why at the inter-annual timescale (and at shorter timescales) values of $E>P$ are feasible in humid environments (Fig. 6b). In addition, the complementary relationship between actual and potential evapotranspiration becomes relevant, because in environments like the Amazon River basin, where $E$ is significant, $E_{\mathrm{p}}$ can decrease and thus, even if $P$ diminishes, in these catchments the aridity index does not increase as much.

\subsubsection{The complementary relationship from the perspective of the scaling approach}

Yang et al. (2006) use the mathematical derivatives of Budyko-type equations to determine whether in a catchment changes in $E$ are mostly dominated by changes in $P$ or $E_{\mathrm{p}}$. For our power law relationship (Eq. 9) the derivatives are as follows:

$$
\begin{aligned}
& \frac{\partial E}{\partial E_{\mathrm{p}}}=k\left[(1-e)\left(\frac{E_{\mathrm{p}}}{P}\right)^{e} \frac{\partial P}{\partial E_{\mathrm{p}}}+e\left(\frac{E_{\mathrm{p}}}{P}\right)^{(e-1)}\right], \\
& \frac{\partial E}{\partial P}=k\left[(1-e)\left(\frac{E_{\mathrm{p}}}{P}\right)^{e}+e\left(\frac{E_{\mathrm{p}}}{P}\right)^{(e-1)} \frac{\partial E_{\mathrm{p}}}{\partial P}\right] .
\end{aligned}
$$

For the analytical derivation of their Budyko-type equation, Yang et al. (2008) considered $P$ and $E_{\mathrm{p}}$ to be completely independent of each other, and thus the terms $\partial P / \partial E_{\mathrm{p}}$ and $\partial E_{\mathrm{p}} / \partial P$ were neglected. On the other hand, while in Fu's mathematical derivation (Fu, 1981) there is no such supposition, studies that have used this formulation, like the one carried out by Yang et al. (2006), do not consider 

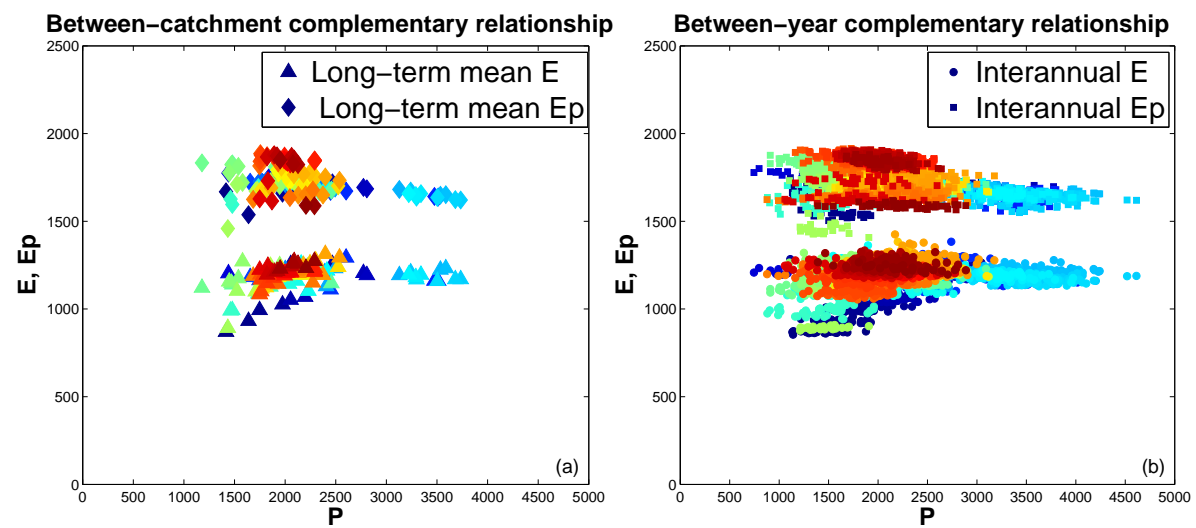

Figure 7. (a) Between-catchment and (b) between-year complementary relationships for the 146 sub-catchments of the Amazon River basin.
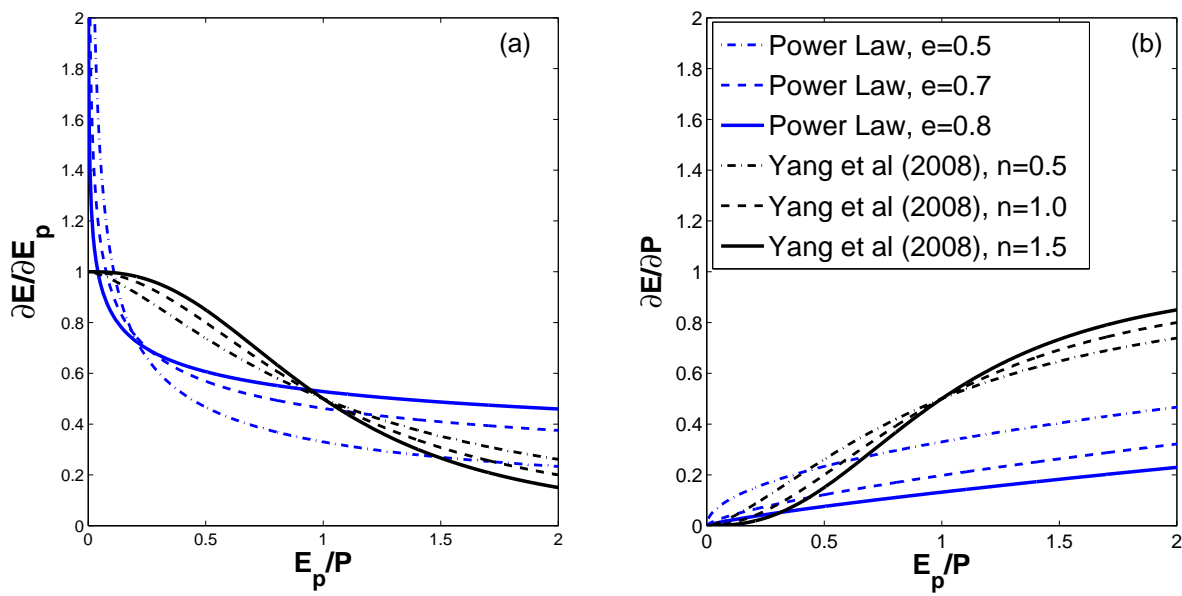

Figure 8. Relationship between (a) $\partial E / \partial E_{\mathrm{p}}$ and (b) $\partial E / \partial P$ with $E_{\mathrm{p}} / P$.

these derivatives when interpreting the complementary relationship based on the Budyko hypothesis. As mentioned previously, assuming that $P$ and $E_{\mathrm{p}}$ are independent variables is not valid since they are correlated through $E$ via the complementary relationship of evapotranspiration, as shown in Fig. 7 for the 146 sub-catchments of the Amazon River basin. Figure 7 a shows between-catchment variability among $E$ and $E_{\mathrm{p}}$ vs. $P$, while Fig. $7 \mathrm{~b}$ shows their between-year variability. Triangles and diamonds are used to denote the relationship between long-term mean $E$ and $E_{\mathrm{p}}$ with respect to $P$ where each marker represents one catchment, whereas circles and squares are used to depict the relationship between inter-annual $E$ and $E_{\mathrm{p}}$ vs. $P$, where each marker represents 1 year. Once more, colors are used to separate catchments. Figure 7 reflects another sign of space-time symmetry within the Amazon River basin, since both inter-annual variability and the long-term mean relationship between $E$ and $E_{\mathrm{p}}$ with $P$ exhibit the same pattern: $E$ increases as $P$ increases, while $E_{\mathrm{p}}$ seems to decrease. To quantify the symmetry between both cases, a linear relationship was fitted to the data. For the case of $E$, the slope and intercept from Fig. 7a were es- timated as 0.04 and 1094, respectively, while from Fig. 7b they were calculated as 0.03 and 1119 . For the case of $E_{\mathrm{p}}$, both slopes were estimated as -0.05 , while the intercepts were 1840 and 1825, respectively. However, in both cases the coefficients of determination $\left(R^{2}\right)$ were very small, and thus these results are not statistically significant. This means that an equation for the relationship between $P$ and $E_{\mathrm{p}}$ could not be obtained empirically. This issue requires further studies, and we believe an effort should be made towards the development of either an empirical or an analytical formulation for the relationship between $P$ and $E_{\mathrm{p}}$ in humid environments, as they are evidently not independent (Fig. 7). Nevertheless, since this formulation is still not available and in order to compare our analytical derivations with those of Yang et al. (2006), in the present study, the terms $\partial P / \partial E_{\mathrm{p}}$ and $\partial E_{\mathrm{p}} / \partial P$ are not considered.

Figure $8 \mathrm{a}$ and $\mathrm{b}$ show the theoretical relationships between $\partial E / \partial E_{\mathrm{p}}$ and $\partial E / \partial P$ with $E_{\mathrm{p}} / P$ using the differential forms of Eqs. (6) and (9) for different values of the parameters $e$ and $n$. For the case of the power law the value of $k$ was fixed at $k=0.6$. This figure shows that for small values of $E_{\mathrm{p}} / P$, the 

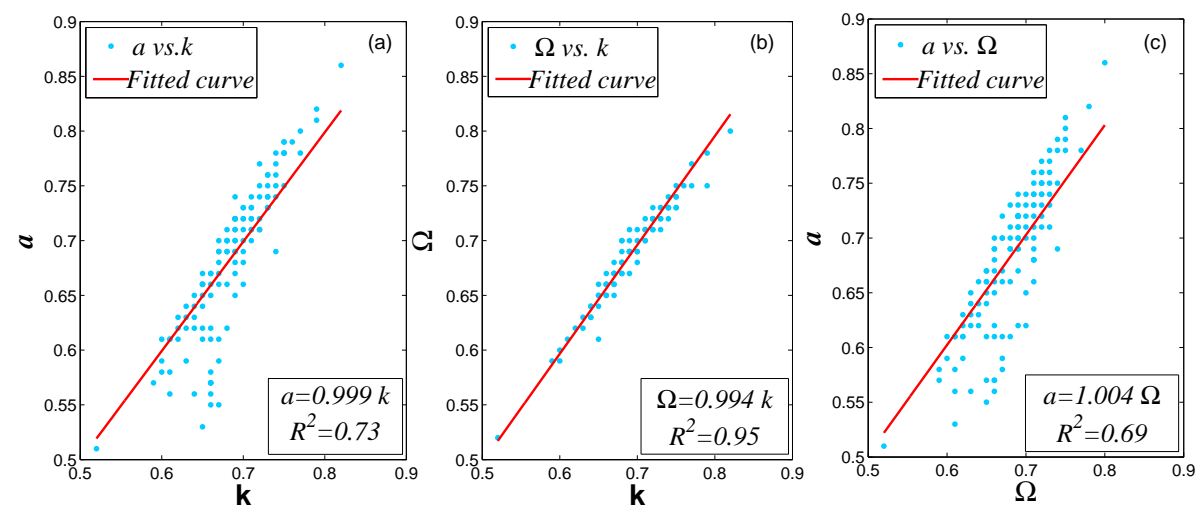

Figure 9. Relationship between $k$ (Eq. 9), $a$ (Cheng et al., 2011) and $\Omega$.

value of $\partial E / \partial E_{\mathrm{p}}$ is larger compared to the value of $\partial E / \partial P$, which means that in humid catchments changes in $E$ are mostly governed by changes in $E_{\mathrm{p}}$ rather than in $P$. Also, it can be seen in Fig. 8a how Budyko-type equations suggest that for very humid environments $\left(E_{\mathrm{p}} / P \rightarrow 0\right)$ changes in $E$ are equal to changes in $E_{\mathrm{p}}\left(\partial E / \partial E_{\mathrm{p}}=1\right)$, which is not necessarily true (Granger, 1989; Kahler and Brutsaert, 2006; Szilagyi, 2007; Lintner et al., 2015). Results remain the same if instead of Eq. (6) the equation proposed by $\mathrm{Fu}$ (1981) is used to depict Fig. 8. However, our scaling approach allows $E$ to change more than $E_{\mathrm{p}}$, which is consistent with the asymmetrical nature of the complementary relationship.

\subsubsection{Between-catchment variability of the parameters at the inter-annual scale}

To explore how the parameters change from catchment to catchment, Eqs. (6), (9) and the linear relationship were fitted to represent the observed inter-annual variability, and thus individual values of $k, e, a, b$ and $n$ were obtained for each catchment. Regarding the goodness of fit (with $95 \%$ confidence bounds in all cases) we found that for the power law the estimated range of the parameters were as follows: $0.52<k<0.82$ and $0.85<e<1.08$ with $0.88<R^{2}<0.99$. For the linear relationship, $0.51<a<$ $0.86,-0.05<b<0.12$ with $0.87<R^{2}<0.99$ and for the Budyko type equation $1.07<n<3.54,0.30<R^{2}<0.88$. Once more the data set is best modelled by either the power law equation or the linear relationship, which in both cases exhibit higher $R^{2}$ than Eq. (6). Also, results found for the power law and for the linear relationship are very similar, as can be seen in the values of both parameters $k$ and $a$. This happens mainly because (i) the intercepts of the linear relationship (b) are close to zero, and (ii) the scaling exponents of the power law $(e)$ are close to 1 . Both characteristics make both equations resemble each other, and assuming $e=1$ and $b=0$, the power law and the linear relationship become the same equation:

$\Psi=k \Phi^{1}=a \Phi+0 \quad$ therefore $a=k$.
Moreover, in the context of our 3-D approach, since $\Psi=$ $E / P$ and $\Phi=E_{\mathrm{p}} / P$, then mathematically from Eq. (12), $a=k=\Omega=E / E_{\mathrm{p}}$. This was tested for the data and is shown in Fig. 9, where $k, a$ and $\Omega$ were plotted against each other. These results indicate that the slope $(a)$ of the linear relationship and the coefficient $(k)$ of the power law are linked through the way that each catchment partitions its energy via evapotranspiration. Nonetheless, taking into account the goodness of fit (Fig. 9) $k$ is actually closer related to $\Omega$ $\left(R^{2}=0.95\right)$ than $a\left(R^{2}=0.69\right)$. This outcome suggests that our scaling approach (Eq. 9) for the Budyko Curve implicitly incorporates the complementary relationship of evapotranspiration (in terms of $\Omega$ ), and thus $k$ becomes a sign of energy limitations in a catchment. This is a consequence of the dependent nature of the studied variables within our 3-D space but also of the physically mutual interdependence between $E, E_{\mathrm{p}}$ and $P$. In particular, in humid environments, where normally there is little water stress, changes in $E$ are mostly dominated by changes in $E_{\mathrm{p}}$ rather than changes in $P$, as evidenced in Fig. 8 and as pointed out by Yang et al. (2006), Zeng and Cai (2015) and Cheng et al. (2011). The latter studied 547 catchments in the continental US and noticed that catchments in subtropical and humid regions exhibited larger slopes and smaller intercepts. They also reformulated the linear relationship to $E=a E_{\mathrm{p}}+b P$ in order to explain physically both parameters, and found that the slope $a$ and intercept $b$ reflect the variability of $E$ with respect to $E_{\mathrm{p}}$ and $P$, respectively. Accordingly, in this study $k$ represents the variability of $E$ due to $E_{\mathrm{p}}$, which is in agreement with results for the long-term mean annual $E, E_{\mathrm{p}}$ and $P$ for each catchment, shown in Fig. 10. As for the scaling exponent, it could also be thought of as a measure of the dependence of $E$ on $E_{\mathrm{p}}$. The more humid the catchment is, the more likely is $e=1$, and thus the more dependent is $E$ on $E_{\mathrm{p}}$ rather than on $P$. Figure 10 a shows the distribution of long-term mean annual $P$ in the Amazon River basin, with values ranging from 1179 to up to $3735 \mathrm{~mm} \mathrm{yr}^{-1}$. A consistent spatial pattern can be found, with the highest precipita- 


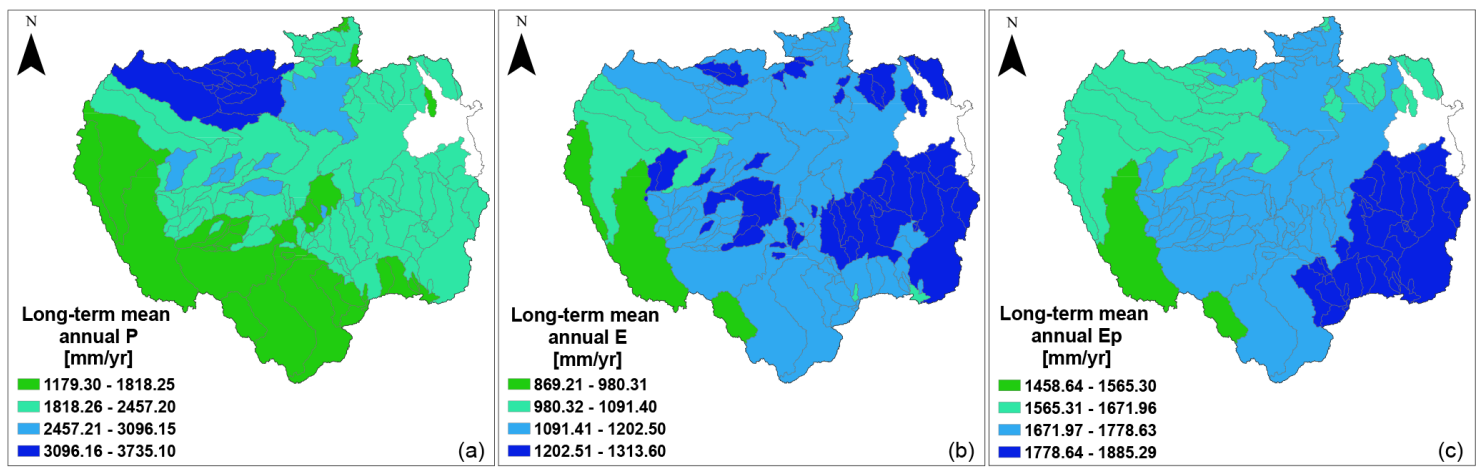

Figure 10. Spatial distribution of the long-term mean annual $P, E$ and $E_{\mathrm{p}}$ across the sub-catchments of the Amazon River basin.

tion occurring in the Colombian Amazon (north-west region) and the lowest precipitation taking place near Peru (western region), Bolivia (south-western region) and some parts of Brazil (south-eastern region). This is consistent with macroclimatic factors such as the migration of the Inter-tropical Convergence Zone (ITZC), and the South Atlantic Convergence Zone (SACZ), land surface-atmosphere interactions (Poveda and Mesa, 1997) as well as interactions between the Amazon and the Andes and the Atlantic Ocean (Nobre et al., 2009; Poveda et al., 2006, 2014; Boers et al., 2015). Yet, the most distinctive spatial pattern can be identified in the regional distribution of $E_{\mathrm{p}}$ (Fig. 10c), with highest values (up to $1885 \mathrm{~mm} \mathrm{yr}^{-1}$ ) over the eastern region of the Amazon River basin, decreasing systematically westwards. Regarding $E$ (Fig. 10b) values range from 869 up to $1313 \mathrm{~mm} \mathrm{yr}^{-1}$ and although some regionalization can be observed it is not as clear as with $P$ or $E_{\mathrm{p}}$. However, it should be noticed that the highest values of $E$ are found not where $P$ is greater, but where $E_{\mathrm{p}}$ is greater, even if values of $P$ are not the highest in that region. In general it can be seen that in the Amazon River basin $E$ follows $E_{\mathrm{p}}$ more than it follows $P$.

\subsubsection{Searching for signs of catchment co-evolution: power law parameters vs. landscape features}

As stated by Troch et al. (2015), catchment co-evolution studies the process of spatial and temporal interactions between water, energy, landscape properties such as bedrock, soils, channel networks, sediments and anthropogenic influences that lead to changes of catchment characteristics and responses. In particular, landscape organization determines how a catchment filters climate into hydrological response in time. For this reason catchment co-evolution is not studied in the time domain, but from a spatial perspective (Perdigão and Blöschl, 2014; Troch et al., 2015).

To determine the possible links between the power law parameters ( $k$ and $e$ ) and the chosen landscape features (topography, groundwater levels and vegetation, described in Sect. 2.2), the Spearman's rank correlation coefficient $(\rho)$ was used. The Spearman's $\rho$ estimates the statistical depen- dence between two variables and how well their relationship can be described using a monotonic function, thus it is a measure of nonlinear co-dependence. If there are no repeated data values, a perfect correlation is obtained when $\rho= \pm 1$. The statistical significance of the results was tested by $p$ values with significance levels set at $5 \%$ as presented in Fig. 11 for $k$. As remarked by Perdigão and Blöschl (2014), high correlations indicate that there might be a relationship between climate and landscape; however, the lack of correlations does not necessarily indicate independence.

In this study, the strongest connection appears to be with vegetation and mean elevation above sea level. Specifically $k(\rho=0.57$, Fig. 11c) and $e(\rho=0.47)$ seem to increase with average maximum green fraction. This result is not surprising, considering that the Amazon River basin is predominantly covered by tropical rainforest, given the relationship that we found previously between $k$ and $\Omega$ and the role of vegetation in evapotranspiration. In addition, both $k$ $(\rho=-0.58$, Fig. 11a) and $e(\rho=-0.28)$ seem to decrease with mean elevation above sea level. The influence of elevation on evapotranspiration (mainly on $E_{\mathrm{p}}$ ) has been studied previously by Jaramillo (2006) for the Colombian Andes, where a decreasing exponential relationship between reference evapotranspiration and elevation for the Cauca and Magdalena river basins was found. Moreover, the inverse relationship between elevation and $E_{\mathrm{p}}$ could be due to the way $E_{\mathrm{p}}$ was estimated, given that Hargreaves et al. (1985) equation is temperature-based and temperature decreases as elevation increases. Results also show that $k(\rho=-0.42$, Fig. 11b) and $e(\rho=-0.30)$ appear to decrease with water table depth, which is also connected to elevation above sea level. Water table depths are larger in the mountains and shallower at lower elevations. Correlations between the other parameters $(a, b$ and $n)$ were also carried out for comparison purposes. The slope of the linear relationship $(a)$ exhibited similar results to $k$, while the intercept $(b)$ exhibited similar results to $e$, but in general $k$ and $e$ showed stronger connections to landscape features than $a$ and $b$. As for the parameter $n$, none of the landscape features shows any statistically significant $\rho$. Thus, even though we are aware that 

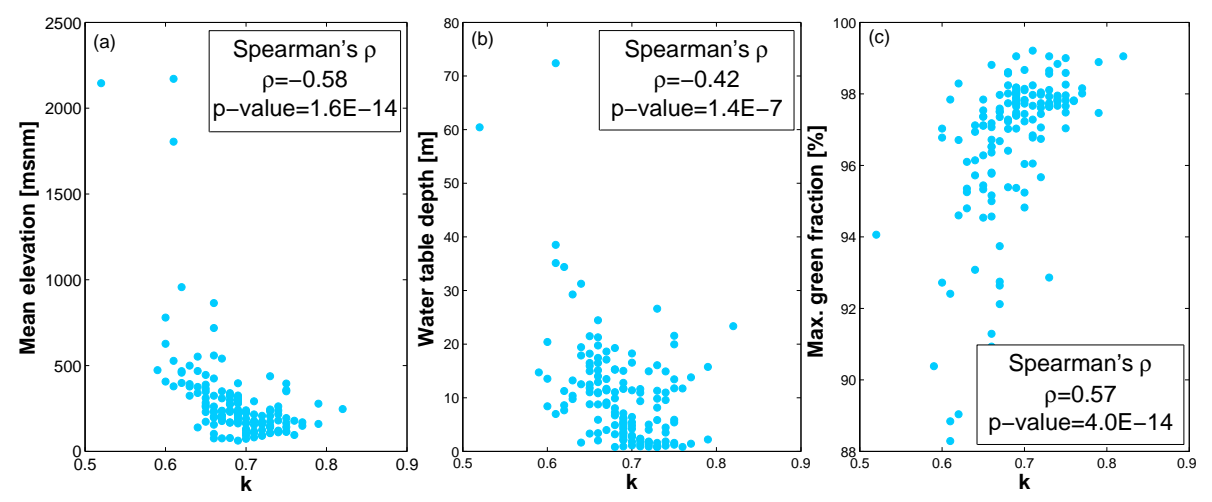

Figure 11. Parameter $k$ vs. landscape features.

our power law is an empirical relationship, landscape features and catchment characteristics are somehow embedded in the values of the associated parameters.

\subsubsection{An alternative equation for evapotranspiration}

Our results show that among the three tested equations the best equation to represent data from the Amazon River basin is the power law (Eq. 9), not only from the perspective of Budyko's framework in humid environments and its physical limits for the 3-D space, but also from the perspective of the complementary relationship, space-time symmetry and catchment co-evolution. At this point it is worth mentioning that the emerging power law was tested for the entire set of 527 catchments in the US and China, with $k=0.63$ and $e=0.46\left(R^{2}=0.61\right)$. It was also tested just for the humid catchments $(\Phi<1)$ from the MOPEX data set with $k=0.74$ and $e=0.96\left(R^{2}=0.60\right)$. In addition, the mean aridity index and evaporation ratio for these data sets are, respectively, $\Phi_{\text {US-China }}=1.28, \Phi_{\text {Mopex }}=0.74, \Omega_{\text {US-China }}=$ 0.63 and $\Omega_{\text {Mopex }}=0.76$, while for the catchments within the Amazon River basin, $\Phi_{\text {Amazon }}=0.86$ and $\Omega_{\text {Amazon }}=0.68$. Recalling that for Amazonia $k=0.66, e=0.83$, this results seemingly show that $\Omega \simeq k$. They also appear to reveal that $k$ decreases with $\Phi$ while $e$ increases. This suggests that our scaling approach could possibly be used as an alternative to the traditional Budyko-type equations in other catchments with different climatic conditions, although it might work better for humid environments. Nevertheless, it should be remembered that for the US and China $E$ was calculated from the water balance equation and therefore estimates of $E$ and $P$ are not mathematically independent, whereas for the Amazon River basin $E$ was estimated using an independent data set based on remote sensors and meteorological observations. For this reason, the universality of the coefficients $(k)$ and scaling exponents $(e)$ of the power law should be explored in the future using diverse data sets. In particular, calculations should be carried out using different and more reliable estimates of $E_{\mathrm{p}}$ considering that there are still difficulties in appropriately estimating the potential of evaporation in very humid environments, especially when there are tropical rainforests and mountains involved such as in the Amazon River basin.

\section{Conclusions}

We have introduced a physically consistent scaling (power law) approach towards a 3-D generalization of the Budyko framework in humid environments, which opens up a new research avenue to understand the coupling between the long-term mean annual water and energy balances catchments, and the hydrological effects brought about by climate change. This new approach combines the water balance from Budyko's perspective with the energy balance from the perspective of the complementary relationship of evapotranspiration. Results for the FAO agro-climatic stations and catchments in the US, China and the Amazon indicate that the well-known Budyko function that relates $\Psi$ vs. $\Phi$ corresponds to a particular bi-dimensional cross section of a broader coupling existing between $\Phi, \Psi$, and $\Omega$ and in turn of the mutual interdependence between precipitation $(P)$, potential evapotranspiration $\left(E_{\mathrm{p}}\right)$ and actual evapotranspiration $(E)$. By studying the mathematical limits of traditional Budyko-type equations (Eq. 5 and 6) we demonstrate that these relationships are unable to capture the physical nature of the water balance in humid environments. This is because they theoretically require that when $\Omega \rightarrow 1$ (very humid environments), $\Phi=0$. We believe this is not possible, given that (i) $E_{\mathrm{p}}$ cannot be zero (non-existent atmospheric demand) and (ii) $P$ is not infinite. We have shown this to be a limitation of the Budyko hypothesis and proposed to overcome it by means of a physically consistent power law $\Psi=k \Phi^{e}$, with $k=0.66$ and $e=0.83\left(R^{2}=0.93\right)$ for Amazonia. The proposed power law is compared with other Budyko-type equations, namely those by Yang et al. (2008) and Cheng et al. (2011). Taking into account the goodness of fit and the ability to comply with the physical limits in our 3D space, our results show that the power law provides a better fit to the data associated with the long-term water balance of the Amazon River basin. Also, our scaling approach is con- 
sistent with the asymmetrical nature of the complementary relationship of evapotranspiration as revealed by Fig. 8 .

By comparing two kinds of variability (long-term mean annual and inter-annual) signs of space-time symmetry were detected in the Amazon River basin, in the sense that our power law can be used to depict both between-catchment variability of long-term mean annual water balance and the between-year variability in individual catchments $(k=0.66$ and $e=0.83$ vs. $k=0.67$ and $e=0.87$, respectively). In addition, the coefficient from the power law $(k)$ is closely related to the partitioning of energy via evapotranspiration $(\Omega)$ in each sub-catchment $\left(\Omega=0.994 k, R^{2}=0.95\right)$. It should be pointed out that $\Omega$ is the variable from the initial 3-D state space that does not appear in the power law. For this reason, we believe that our scaling approach (Eq. 9) implicitly incorporates the complementary relationship of evapotranspiration into the formulations of the Budyko curve. Thus, the parameter $k$ becomes a sign of energy limitations in a catchment. In general, the higher the scaling exponent (e), the more will $\Omega$ and $k$ resemble each other. Mathematically $\Omega=k$ if $e=1$. This is a consequence of the dependent nature of the studied variables within our 3-D space but also of the physically mutual interdependence between $E, E_{\mathrm{p}}$ and $P$. In addition, signs of catchment co-evolution were detected since the spatial patterns of the water balance parameters were found to be associated with relevant landscape features. In general, $k$ and $e$, seem to decrease with both mean elevation above sea level and water table depth and to increase with the average maximum green fraction, which was used as a proxy for vegetation. In both cases these could be related to the role of vegetation in evapotranspiration and also to the fact that the estimation of $E_{\mathrm{p}}$ was carried out with a temperature-based equation. None of the landscape features exhibited any statistically significant relationship with the parameter $n$. Thus, landscape features and catchment characteristics are somehow embedded in the values of the associated parameters of our power law.

Finally, our power law equation was used to model data from catchments in the US and China. Results show that our scaling approach could potentially be used as an alternative equation to traditional Budyko-type equations, mostly in humid environments, given that it is not only physically consistent, but it is also suitable from the perspective of space-time symmetry and catchment co-evolution, taking into account the feedbacks between topography, vegetation and water in soils.

The scaling approach proposed in the present study offers several advantages from both theoretical and practical viewpoints. In particular, the space-time symmetry detected for the Amazon River basin, could provide a framework for extrapolating between "climatic scales" with climate represented by means of $\Phi$ both in the long-term and inter-annual variability. Besides, given that our 3-D space and the proposed scaling approach are able to capture the mutual interdependence of $E, E_{\mathrm{p}}$ and $P$, this framework could be po- tentially used for studies of climatic change, in particular to understand changes in $E$ given both changes in $E_{\mathrm{p}}$ and $P$. This will be explored in the future. However, further analyses will be required in other catchments and other humid environments so that the scaling exponents and coefficients of the power law relationship can be confirmed using different data sets. This is a subject that is left for future research.

Acknowledgements. To all the institutions that provided us with access to the different data sets. The work by A. M. Carmona is supported by COLCIENCIAS. The work of G. Poveda and S. M. Vallejo-Bernal is supported by Universidad Nacional de Colombia, Sede Medellín, as a contribution to the AMAZALERT and VACEA programs. The work of E. Bustamante is supported by the Department of Mathematics at Universidad Nacional de Colombia, Sede Medellín. We also thank the reviewers and the Editor for their relevant comments and observations.

Edited by: D. Wang

\section{References}

Arora, V. K.: The use of the aridity index to assess climate change effect on annual runoff, J. Hydrol., 265, 164-177, doi:10.1016/S0022-1694(02)00101-4, 2002.

Blöschl, G., Sivapalan, M., Wagener, T., Viglione, A., and Savenije, H. H. G.: Runoff Prediction in Ungauged Basins: Synthesis Across Processes, Places and Scales, Cambridge University Press, Cambridge, UK, 2013.

Boers, N., Bookhagen, B., Marwan, N., and Kurths, J.: Spatiotemporal characteristics and synchronization of extreme rainfall in South America with focus on the Andes Mountain range, Clim. Dynam., 46, 601-617, doi:10.1007/s00382-015-2601-6, 2015.

Bouchet, R. J.: Evapotranspiration reelle et potentielle signification climatique, General Assembly Berkley, Int. Assoc. Sci. Hydrol. Pub., 62, 134-142, 1963.

Brown, J. H., Gupta, V. K., Li, B., Restrepo, C., and West, G. B.: The fractal nature of nature: power laws, ecological complexity and biodiversity, Philos. T. Roy. Soc. B, 357, 619-626, 2002.

Broxton, P. D., Zeng, X., Sulla-Menashe, D., and Troch, P. A.: A global land cover climatology using MODIS data, J. Appl. Meteorol. Clim., 53, 1593-1605, doi:10.1175/JAMC-D-13-0270.1, 2014.

Budyko, M. I.: The Heat Balance of the Earth's Surface, Natl. Weather Serv., US Dep. of Commer., Washington, D.C., USA, 1958.

Budyko, M. I.: Climate and Life, Academic Press, New York, USA, p. 508, 1974.

Carmona, A. M., Sivapalan, M., Yaeger, M. A., and Poveda, G.: Regional patterns of interannual variability of catchment water balances across the continental U.S.: A Budyko framework, Water Resour. Res., 50, 9177-9193, doi:10.1002/2014WR016013, 2014.

Cheng, L., Xu, Z., Wang, D., and Cai, X.: Assessing interannual variability of evapotranspiration at the river basin scale using satellite-based evapotranspiration data sets, Water Resour. Res., 47, W09509, doi:10.1029/2011WR010636, 2011. 
Choudhury, B. J.: Evaluation of an empirical equation for annual evaporation using field observations and results from a biophysical model, J. Hydrol., 216, 99-110, doi:10.1016/S00221694(98)00293-5, 1999.

Dominguez, F., Kumar, P., Liang, X., and Ting, M.: Impact of atmospheric moisture storage on precipitation recycling, J. Climate, 19, 1513-1530, doi:10.1175/JCLI3691.1, 2006.

Donohue, R. J., Roderick, M. L., and McVicar, T. R.: On the importance of including vegetation dynamics in Budyko's hydrological model, Hydrol. Earth Syst. Sci., 11, 983-995, doi:10.5194/hess11-983-2007, 2007.

Duan, Q., Schaake, J., Andréassian, V., Franks S., Goteti, G., Gupta, H. V., Gusev, Y. M., Habets, F., Hall, A., Hay, L., Hogue, T., Huang, M., Leavesley, G., Liang, X., Nasonova, O. N., Noilhan, J., Oudin, L., Sorooshian, S., Wagener, T., and Wood, E. F.: Model parameter estimation experiment (MOPEX): an overview of science strategy and major results from the second and third workshops, J. Hydrol., 320, 3-17, doi:10.1016/j.jhydrol.2005.07.031, 2006.

Elthair, E. A. B. and Bras, R. L.: Precipitation recycling in the Amazon basin, Q. J. Roy. Meteor. Soc., 120, 861-880, 1994.

Fan, Y., Li, H. and Miguez-Macho, G.: Global patterns of groundwater table depth, Science, 339, 940-943, 2013.

Farnsworth, R. K., Thompson, E. S., and Peck, E. L.: Evaporation Atlas for the Contiguous 48 United States, NOAA Tech. Rep. NWS 33, NOAA, Washington, DC, USA, 1982.

$\mathrm{Fu}, \mathrm{B}$. P.: On the calculation of the evaporation from land surface, Sci. Atmos. Sin., 5, 23-31, 1981.

Granger, R. J.: A complementary relationship approach for evaporation from nonsaturated surfaces, J. Hydrol., 111, 31-38, 1989.

Greve, P., Gudmundsson, L., Orlowsky, B., and Seneviratne, S. I.: The Budyko framework beyond stationarity, Hydrol. Earth Syst. Sci. Discuss., 12, 6799-6830, doi:10.5194/hessd-12-6799-2015, 2015.

Gupta, V. K. and Dawdy, D. R.: Physical interpretations of regional variations in the scaling exponents of flood quantiles, Hydrol. Process., 9, 347-361, doi:10.1002/hyp.3360090309, 1995.

Han, S., Tian, F., and Hu, H.: Positive or negative correlation between actual and potential evaporation? Evaluating using a onlinear complementary relationship model, Water Resour. Res., 50, 1322-1336, doi:10.1002/2013WR014151, 2014.

Hargreaves, G. L., Hargreaves, G. H., and Riley, J. P.: Irrigation water requirements for Senegal River basin, J. Irrig. Drain. E.ASCE, 111, 265-275, 1985.

Hobbins, M. T., Ramírez J. A., and Brown, T. C.: The complementary relationship in estimation of regional evapotranspiration: an enhanced advection-aridity model, Water Resour. Res., 37, 1389-1403, 2001.

Jaramillo, A.: Evapotranspiración de referencia en la región Andina de Colombia, Cenicafé, 57, 288-298, 2006.

Jung, M., Reichstein, M., Ciais, P., Seneviratne, S. I., Sheffield, J., Goulden, M. L., Bonan, G., Cescatti, A., Chen, J., De Jeu, R., Dolman, A. J., Eugster, W., Gerten, D., Gianelle, D., Gobron, N., Heinke, J., Kimball, J., Law, B. E., Montagnani, L., Mu, Q., Mueller, B., Oleson, K., Papale, D., Richardson, A. D., Roupsard, O., Running, S., Tomelleri, E., Viovy, N., Weber, U., Williams, C., Wood, E., Zaehle, S., and Zhang, K.: Recent decline in the global land evapotranspiration trend due to limited moisture supply, Nature, 467, 951-954, 2010.
Kahler, D. M. and Brutsaert, W.: Complementary relationship between daily evaporation in the environment and pan evaporation, Water Resour. Res. 42, W05413, doi:10.1029/2005WR004541, 2006.

Lintner, B. R., Gentine, P., Findell, K. L., and Salvucci, G. D.: The Budyko and complementary relationships in an idealized model of large-scale land-atmosphere coupling, Hydrol. Earth Syst. Sci., 19, 2119-2131, doi:10.5194/hess-19-2119-2015, 2015.

Ma, Z., Kang, S., Zhang, L., Tong, L., and Su, X.: Analysis of impacts of climate variability and human activity on streamflow for a river basin in arid region of northwest China, J. Hydrol., 352, 239-249, doi:10.1016/j.jhydrol.2007.12.022, 2008.

Mandelbrot, B. B.: The Fractal Geometry of Nature, Freeman and Co., New York, USA, 1983.

Mezentsev, V. S.: More on the calculation of average total evaporation, Meteorol. Gidrol, 5, 24-26, 1955.

Milly, P. C. D.: Climate, soil water storage, and the average annual water balance, Water Resour. Res., 30, 2143-2156, 1994.

Monteith, J. L.: Evaporation and environment, Symp. Soc. Exp. Biol., 19, 205-224, 1965.

Morton, F. I.: Operational estimates of areal evapotranspiration and their significance to the science and practice of hydrology, J. Hydrol., 66, 1-76, 1983.

Nobre, C. A., Obregón, G., Marengo, J., Fu, R., and Poveda, G.: Characteristics of Amazonian climate: main features, P. Geophys. Mon. Ser, 186, 149-162, 2009.

Ol'dekop, E. M.: On evaporation from the surface of river basins, Trans. Meteorol. Obs. Univ. Tartu, 4, 1911.

Parzen, E.: Stochastic Processes, in: Volume 24 of Classics in Applied Mathematics, SIAM, Philadelphia, USA, 324 pp., 1999.

Penman, H. L.: Natural evaporation from open water, bare soil and grass, P. Roy. Soc. Lond. A, 193, 120-145, 1948.

Perdigão, R. A. P. and Blöschl, G.: Spatiotemporal flood sensitivity to annual precipitation: evidence for landscapeclimate coevolution, Water Resour. Res., 50, 5492-5509, doi:10.1002/2014WR015365, 2014.

Pike, J. G.: The estimation of annual runoff from meteorological data in a tropical climate, J. Hydrol., 12, 2116-2123, 1964.

Poveda, G. and Mesa, O. J.: Feedbacks between hydrological processes in tropical South America and large-scale oceanatmospheric phenomena, J. Climate, 10, 2690-2702, 1997.

Poveda, G., Waylen, P., and Pulwarty, R.: Annual and inter-annual variability of present climate in northern South America and southern Mesoamerica, Palaeogeogr. Palaeocl., 234, 3-27, 2006.

Poveda, G., Jaramillo, L., and Vallejo, L. F.: Seasonal precipitation patterns along pathways of South American lowlevel jets and aerial rivers, Water Resour. Res., 50, 98-118, doi:10.1002/2013WR014087, 2014.

Renner, M. and Bernhofer, C.: Applying simple water-energy balance frameworks to predict the climate sensitivity of streamflow over the continental United States, Hydrol. Earth Syst. Sci., 16, 2531-2546, doi:10.5194/hess-16-2531-2012, 2012.

Renner, M., Seppelt, R., and Bernhofer, C.: Evaluation of waterenergy balance frameworks to predict the sensitivity of streamflow to climate change, Hydrol. Earth Syst. Sci., 16, 1419-1433, doi:10.5194/hess-16-1419-2012, 2012.

Roderick, M. L. and Farquhar, G. D.: A simple framework for relating variations in runoff to variations in climatic conditions 
and river basin properties, Water Resour. Res., 47, W00G07, doi:10.1029/2010WR009826, 2011.

Rodriguez-Iturbe, I. and Rinaldo, A.: Fractal River Basins: Chance and Self-Organization, Cambridge Univ. Press, New York, USA, 1997.

Schreiber, P.: Über die Beziehungen zwischen dem Niederschlag und der Wasserführung der Flüsse in Mitteleuropa, Z. Meteorol. 21, 441-452, 1904.

Shuttleworth, W. J.: Evaporation from Amazonian rainforest, Philos. T. Roy. Soc. B, 233, 321-346, 1988.

Sivapalan, M., Yaeger, M. A., Harman, C. J., Xu, X., and Troch, P. A.: Functional model of water balance variability at the catchment scale: 1. Evidence of hydrologic similarity and space-time symmetry, Water Resour. Res., 47, W02522, doi:10.1029/2010WR009568, 2011.

Sposito, G.: Scale Dependence and Scale Invariance in Hydrology, Cambridge Univ. Press., Cambridge, UK, 1998.

Szilagyi, J.: On the inherent asymmetric nature of the complementary relationship of evaporation, Geophys. Res. Lett., 34, L02405, doi:10.1029/2006GL028708, 2007.

Szilagyi, J. and Jozsa, J.: Complementary relationship of evaporation and the mean annual water-energy balance, Water Resour. Res., 45, W09201, doi:10.1029/2009WR008129, 2009.

Thornthwaite, C. W.: An approach toward a rational classification of climate, Geogr. Rev., 38, 55-94, doi:10.2307/210739, 1948.

Trabucco, A. and Zomer, R. J.: Global Aridity Index (GlobalAridity) and Global Potential Evapo-Transpiration (Global-PET) Geospatial Database, CGIAR Consortium for Spatial Information, Published online, available from the CGIAR-CSI GeoPortal at: http://www.csi.cgiar.org (last access: 16 March 2015), 2009.

Troch, P. A., Lahmers, T., Meira, A., Mukherjee, R., Pedersen, J. W., Roy, T., and Valdés-Pineda, R.: Catchment coevolution: a useful framework for improving predictions of hydrological change?, Water Resour. Res., 51, 4903-4922, doi:10.1002/2015WR017032, 2015.

Turc, L.: Le bilan d'eau des sols relations entre les precipitations, l'evaporation et et l'ecoulement, Ann. Agron., 5, 491-595, 1954.

Turcotte, D.: Fractals and Chaos in Geology and Geophysics, Cambridge University Press, Cambridge, UK, 398 pp., 1997.

Vallejo-Bernal, S. M., Carmona, A. M., and Poveda, G.: Validation of Potential Evapotranspiration from CRU TS v. 3.22 database through vegetation activity in the Amazon River Basin, in preparation, 2016.
Wang, D. and Hejazi, M.: Quantifying the relative contribution of the climate and direct human impacts on mean annual streamflow in the contiguous United States, Water Resour. Res., 47, W00J12, doi:10.1029/2010WR010283, 2011.

$\mathrm{Xu}, \mathrm{C}$. Y. and Singh, V. P.: Evaluation of three complementary relationship evapotranspiration models by water balance approach to estimate actual regional evapotranspiration in different climatic regions, J. Hydrol., 308, 105-121, 2005.

Yang, D., Sun, F., Liu, Z., Cong, Z., and Lei, Z.: Interpreting the complementary relationship in non-humid environments based on the Budyko and Penman hypotheses, Geophys. Res. Lett., 33, L18402, doi:10.1029/2006GL027657, 2006.

Yang, D., Sun, F., Liu, Z., Cong, Z., Ni, G., and Lei, Z.: Analyzing spatial and temporal variability of annual water-energy balance in nonhumid regions of China using the Budyko hypothesis, Water Resour. Res., 43, 1-12, doi:10.1029/2006WR005224, 2007.

Yang, H., Yang, D., Lei, Z., and Sun, F.: New analytical derivation of the mean annual water-energy balance equation, Water Resour. Res., 44, W03410, doi:10.1029/2007WR006135, 2008.

Zemp, D. C., Schleussner, C.-F., Barbosa, H. M. J., van der Ent, R. J., Donges, J. F., Heinke, J., Sampaio, G., and Rammig, A.: On the importance of cascading moisture recycling in South America, Atmos. Chem. Phys., 14, 13337-13359, doi:10.5194/acp-1413337-2014, 2014.

Zeng, R. and Cai, X.: Assessing the temporal variance of evapotranspiration considering climate and catchment storage factors, Adv. Water Resour., 79, 51-60, 2015.

Zhang, L., Dawes, W. R., and Walker, G. R.: Response of mean annual evapotranspiration to vegetation changes at river basin scale, Water Resour. Res., 37, 701-708, 2001.

Zhang, L., Potter, N., Hickel, K., Zhang, Y., and Shao, Q.: Water balance modeling over variable time scales based on the Budyko framework Model development and testing, J. Hydrol., 360, 117 131, doi:10.1016/j.jhydrol.2008.07.021, 2008.

Zhou, S., Yu, B., Huang, Y., and Wang, G.: The complementary relationship and generation of the Budyko functions, Geophys. Res. Lett., 42, 1781-1790, doi:10.1002/2015GL063511, 2015. 